\title{
ANALISIS PERBAIKAN TERHADAP ANTRIAN PADA POM BENSIN RAWALUMBU
}

\author{
Hendy Tannady \\ Program Studi Manajemen, Universitas Pembangunan Jaya \\ e-mail: hendytannady@gmail.com
}

\begin{abstract}
ABSTRAK
Tujuan dari penelitian ini adalah untuk memperbaiki tingkat antrian yang ada pada pom bensin Pertamina yang berlokasi pada Rawalumbu, Bekasi. Tujuan khusus dari penelitian ini adalah untuk mengetahui jumlah penambahan stasiun yang optimal untuk mengurangi tingkat antrian tersebut, dan juga untuk mengetahui bentuk dari jalur yang diubah ketika mendapatkan jumlah station yang optimal. Dalam penelitian ini jumlah stasiun yang didapat berjumlah 7 station dengan meminimalkan tingkat antrian sebesar 2,65\%. Sehingga, antrian dapat berkurang dan pengisian dapat berjalan dengan optimal. Hasil didapat melalui suatu simulasi permodelan dengan menggunakan suatu software yaitu dengan aplikasi Promodel.
\end{abstract}

Kata kunci: antrian, simulasi sistem, pom bensin, promodel.

\section{ABSTRACT}

The purpose of this study is to improve the level of the queue at the gas station in Rawalumbu, Bekasi. The specific purpose of this study is to determine the optimal number of stations to reduce the queue level, and also to find out the form of the lane that is compiled to get the optimal number of stations. In this study the number of stations that can be accepted by 7 stations with the acquisition of a queue level of $2.65 \%$. Increasingly, the queue can be reduced and the filling can run optimally. The results obtained through a modeling simulation using a software that is with the Promodel application.

Keywords: quеие, simulation system, gas station, promodel.

\section{PENDAHULUAN}

Dunia usaha pada saat ini dihadapkan pada persaingan yang semakin terbuka dan semakin ketat diberbagai bidangya [1,2,3]. Persaingan bukan hanya mengenai produktivitas namun kualitas jasa yang diberikan [4]. Bahan Bakar merupakan salah satu usaha yang dimonopoli pemerintah yaitu Pertamina. Banyak perusahaan bahan bakar lain yang telah masuk ke Indonesia seperti Shell, Total yang menjadi pesaing bagi Pertamina, sehingga peningkatan pelayanan kualitas menjadi hal yang sangat penting bagi pihak SPBU Pertamina. Salah satu permasalahan yang terjadi pada Pertamina merupakan tingkat pelayanan yang kurang sehingga menyebabkan tingkat antrian yang panjang dalam pengisian bahan bakar. Penelitian ini membahas antrian yang terdapat pada pom bensin yang terdapat di Rawalumbu, Bekasi. Pom bensin tersebut terkategori memiliki antrian yang panjang dikarenakan hanya mempunyai satu pom khusus motor yang terdiri dari pertalite dan pertamax. Pada jam kerja terjadi antrian yang sangat panjang dalam pengisisan bensin sehingga terjadinya keterlambatan waktu bagi konsumen yang hendak melanjutkan perjalanan ke tempat tujuan mereka. Dalam hal ini, peneliti akan mengoptimalkan sistem kerja dengan meminimalkan panjang antrian. Penulis akan melakukan simulasi dengan menggunakan aplikasi promodel.

Beberapa penelitian terdahulu yang mendukung penelitian ini adalah analisa tata letak pabrik untuk meminimalisasi material handling pada pabrik sheet metal dengan software promodel [5], optimalisasi sistem pelayanan untuk mengurangi antrian dengan pendekatan simulasi mengunakan software promodel pada SPBU Kadipaten di Majalengka [6], analisis kemacetan di jalan lingkar dalam kota Jakarta (Gerbang Tol Cililitan) [7] dan simulasi sistem proses produksi di PT. Jakarta Cakratunggal Stell Mills [8]. 


\section{Hendy Tannady}

Tujuan penelitian ini adalah mengetahui jumlah dari station agar mengurangi antrian, mengetahui skenario dari proses jalur dari pom bensin dan mengetahui pengaruh dari proses simulasi yang telah dilakukan pada pom bensin Rawalumbu.

\section{METODE PENELITIAN}

\section{Simulasi, Sistem dan Model}

Simulasi sebagai cara untuk menghasilkan kondisi dari situasi dengan model untuk studi menguji atau training, dan lain-lain [9]. Simulasi juga merupakan kumpulan metode dan aplikasi yang digunakan untuk meniru perilaku suatu sistem, kadang dilakukan keputusan dengan mencontoh atau mempergunakan gambaran sebenarnya dari suatu sistem kehidupan dunia nyata tanpa harus mengalaminya pada keadaan yang sesungguhnya [10]. Simulasi merupakan sebuah usaha untuk menyalin fitur, tampilan dan karakteristik sebuah sistem nyata [11]. Gagasan di balik simulasi adalah untuk meniru sebuah situasi dalam dunia nyata secara matematis, kemudian untuk mempelajari karakteristik operasi tersebut, dan menggunakan komputer dengan software yang sesuai serta menarik kesimpulan dan mengambil keputusan tindakan berdasarkan kepada hasil simulasi [12].

Sistem sebagai kumpulan komponen-komponen yang berinteraksi dan bereaksi antar atribut komponen-komponen untuk mencapai suatu tujuan akhir yang logis [9]. Hukum sistem dipandang sebagai kumpulan aturan-aturan yang membatasi baik oleh kapasitas sistem itu sendiri maupun lingkungan tempat sistem itu berada, untuk menjamin keserasian dan keadilan. Sistem didefinisikan sebagai kumpulan anggota misalnya orang atau mesin yang berperilaku dan saling berinteraksi untuk mencapai tujuan yang logis. Kumpulan dari anggota yang membentuk sebuah sistem mungkin hanya sebagian dari seluruh sistem yang lain [13]. Sistem dikategorikan menjadi dua tipe yaitu diskrit dan kontinu. Model diartikan sebagai tiruan dari kondisi yang sebenarnya [6]. Simulasi pemodelan adalah suatu langkah awal yang dilakukan untuk pembuatan suatu rekayasa perangkat lunak dari sebuah sistem yang akan disimulasikan [14].

\section{Simulasi Promodel}

Promodel (Production Modeler) adalah salah satu perangkat lunak yang dapat digunakan untuk memodelkan berbagai sistem manufaktur dan jasa [8]. Promodel dari Perusahaan Promodel. Ini dirancang untuk penilaian, perencanaan dan desain produksi, penyimpanan, logistik dan operasional lainnya dan kebutuhan strategis [15]. Keuntungan menggunakan software Promodel adalah waktu perhitungan yang lebih cepat dan praktis serta akurasi yang baik [5]. Dalam Promodel selama simulasi berlangsung dapat diamati animasi dari kegiatan yang sedang berlangsung dan hasilnya akan ditampilkan dalam bentuk tabel maupun grafik yang memudahkan untuk penganalisisan [8].

\section{Location}

Hal-hal yang diperhatikan dalam pembuatan Promodel adalah:

Dalam Promodel, location merupakan tempat atau layout dari model suatu sistem, yang berisi gambar latar belakang seperti mesin-mesin, stasiun kerja, gudang penyimpanan, dan sebagainya. Lokasi adalah komponen statis sehingga tidak ikut bergerak selama simulasi dijalankan.

2. Entity

Entity merupakan sesuatu yang akan menjadi objek yang akan diproses dalam model sistem, seperti: bahan baku, produk setengah jadi, produk jadi, produk reject, bahkan lembar kerja.

3. Path Network

Path Networks merupakan lintasan kerja Resources yang terdiri dari node-node dan lintasan yang menghubungkan antara node yang satu dengan node yang lainnya. 


\section{Resources}

Resources merupakan manusia, peralatan atau perlengkapan kerja lainnya yang digunakan/bertugas memindahkan entity.

5. Arrivals

Arrivals menunjukkan tempat atau lokasi dimana entitas tiba pada suatu sistem yang diamati untuk pertama kali.

6. Processing

Processing merupakan operasi yang terjadi di dalam sistem dan dilakukan pada lokasi dan antar lokasi.

\section{HASIL DAN PEMBAHASAN}

Pengambilan data dilakukan melalui observasi pada Senin tanggal 26 Agustus 2019 pada pukul 07.00-09.00 dan Selasa 27 Maret 2019 pada pukul 16.00-18.00 di SPBU Pertamina Rawalumbu, Bekasi dan terdapat satu station pengisian bahan bakar. Dari data yang telah dikumpulkan, pengolahan data dilakukan melalui aplikasi minitab untuk mencari distribusi datanya. Gambar 1 menunjukkan distribusi data antrian

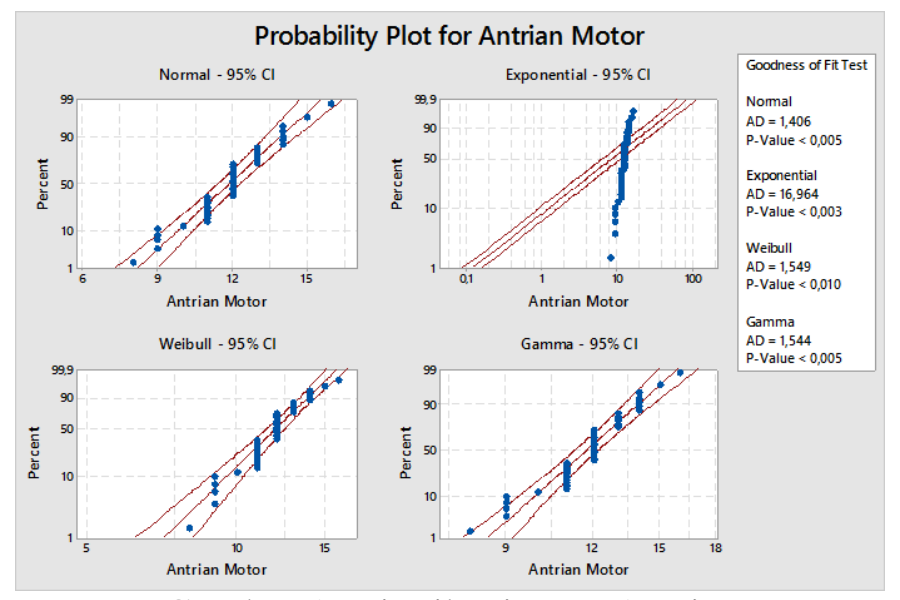

Gambar 1. Distribusi Data Antrian

Dari Pengolahan data antrian tersebut, ditemukan distribusi data pada antrian motor yaitu distribusi exponential yang bernilai lebih besar di atas P-Value, dengan nilai mean 11,8958 dan standart deviasi 1,58771. Gambar 2 menunjukkan hasil distribusi data dari pengolahan data waktu pengisian bahan bakar.

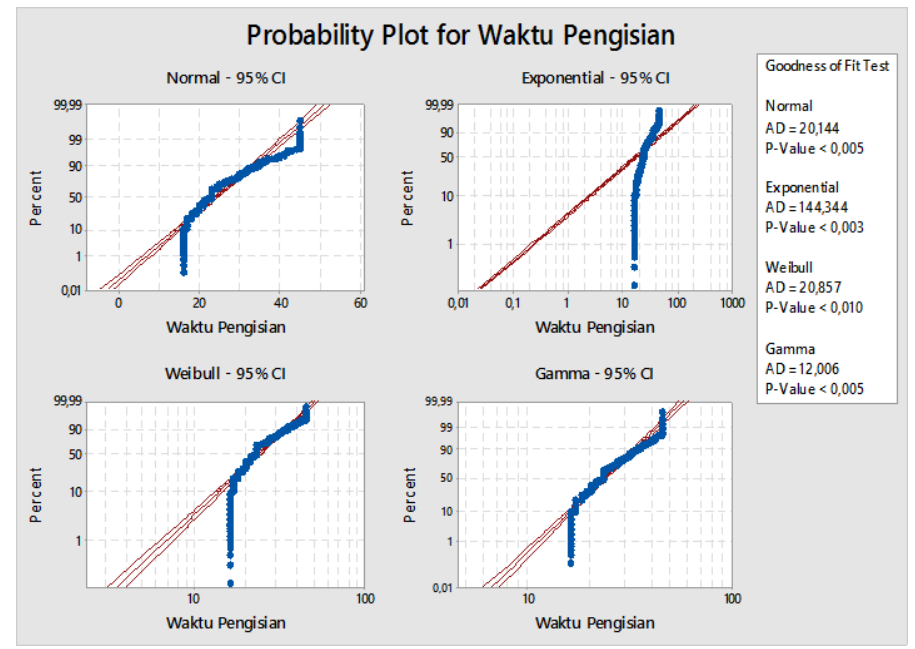

Gambar 2. Distribusi Data Waktu Pengisian 


\section{Hendy Tannady}

Dari hasil pengolahan data waktu pengisian, ditemukan distribusi data yaitu data exponential yang bernilai lebih besar di atas p-value, dengan nilai mean 24,2048 dan standart deviasi 7,24745. Setelah distribusi data diketahui, data tersebut di input ke dalam aplikasi promodel. Tabel 1 menunjukkan data yang diperlukan dalam men-simulasikan ke dalam promodel.

\begin{tabular}{ccc}
\multicolumn{3}{c}{ Tabel 1. Data Keperluan Simulasi } \\
\hline No. & Build & Name \\
\hline 1 & Location & Antrian \\
2 & Location & Station \\
3 & Location & Exit \\
4 & Entities & Motor \\
5 & Path Network & Node \\
6 & Resources & Operator Manusia \\
\hline
\end{tabular}

Setelah dilakukan simulasi penambahan station terhadap 571 motor, terdapat 7 station pengisian bahan bakar dengan hasil yang optimal dalam meminimalkan antrian yang terdapat. Tabel 2 menunjukkan hasil simulasi promodel sebelum ditambahkan station. Dari hasil Tabel 2 dapat dilihat utilization pada antrian sebesar 78,92\%.

Tabel 2. Hasil Simulasi Promodel Sebelum Penambahan Station

\begin{tabular}{cccccc}
\hline Name & $\begin{array}{c}\text { Scheduled } \\
\text { Time }\end{array}$ & Capacity & $\begin{array}{c}\text { Total } \\
\text { Entries }\end{array}$ & $\begin{array}{c}\text { Avg } \\
\text { Time/Entry }\end{array}$ & $\begin{array}{c}\text { \% } \\
\text { Utilization }\end{array}$ \\
\hline Station & 5,79 & 1 & 13 & 26,72161 & 99,937 \\
Antrian & 5,79 & 999999 & 13 & 65,76715 & 78,929 \\
\hline
\end{tabular}

Kemudian dilakukan berbagai simulasi dengan menambahkan jumlah station, hasil penambahan 2 station adalah nilai utilisasi pada antrian sebesar $75,41 \%$. Hasil penambahan 3 station adalah nilai utilisasi sebesar $51,19 \%$. Hasil penambahan 4 station adalah nilai utilisasi sebesar $54,77 \%$. Hasil penambahan 5 station adalah nilai utilisasi sebesar $34,49 \%$. Hasil penambahan 6 station adalah nilai utilisasi sebesar 13,55\%. Hasil penambahan 7 station adalah nilai utilisasi 2,65\%. Berdasarkan hasil simulasi, dapat digambarkan opsi jalur yang akan dipilih memiliki bentuk sebagai berikut.

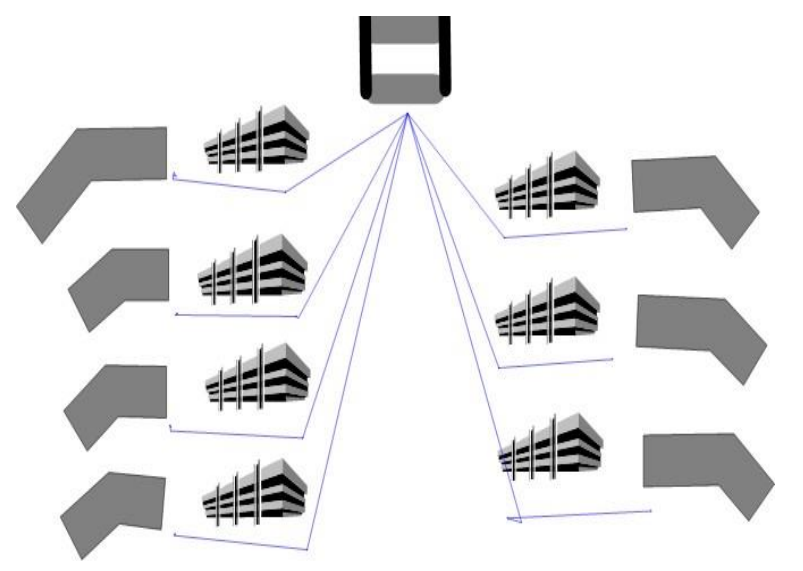

Gambar 3. Permodelan Opsi Jalur Pom Bensin

\section{KESIMPULAN DAN SARAN}

Permodelan simulasi dalam rangka penambahan station dilakukan sebanyak 7 kali dengan nilai \% utilization sebesar $2,65 \%$ pada antrian, sehingga terjadinya pengurangan 
antrian pada SPBU Rawalumbu. Opsi jalur yang disarankan pada manajemen adalah berbentuk seperti Gambar 3. Dengan menggunakan simulasi promodel dapat melihat tingkat dari antrian dan dapat meminimalkan utilization dari tingkat antrian yang terjadi pada pom bensin Rawalumbu, Promodel juga dapat memperlihatkan bentuk jalur yang dapat dipilih untuk rute masuk dan keluarnya pada pom bensin Rawalumbu. Saran yang dapat diberikan adalah manajemen SPBU Pertamina di Rawalumbu, Bekasi dapat mempertimbangkan penambahan station pengisian bahan bakar sesuai dengan kesimpulan hasil penelitian.

\section{DAFTAR PUSTAKA}

[1] Rahayu, M., Rasid, F., \& Tannady, H. 2018. Effects of Self Efficacy, Job Satisfaction, and Work Culture Toward Performance of Telemarketing Staff in Banking Sector. South East Asia Journal of Contemporary Business, Economics and Law, 16(5), 47-52.

[2] Rahayu, M., Rasid, F., \& Tannady, H. 2019. The Effect of Career Training and Development on Job Satisfaction and its Implications for the Organizational Commitment of Regional Secretariat (SETDA) Employees of Jambi Provincial Government. International Review of Management and Marketing, 9(1), 79-89.

[3] Tannady, H., \& Sitorus, T. 2017. Role Of Compensation, Organization Culture, And Leadership On Working Motivation Of Faculty Member (Study Case: Universities In North Jakarta). IOSR-Journal of Business \& Management, 19(10), 41-47.

[4] Gunawan, C. V., \& Tannady, H. 2016. Analisis Kinerja Proses Dan Identifikasi Cacat Dominan Pada Pembuatan Bag Dengan Metode Statistical Proses Control (Studi Kasus: Pabrik Alat Kesehatan PT. xyz, Serang, Banten). J@ti Undip: Jurnal Teknik Industri, 11(1), 9-14.

[5] Lestari, S. 2014. Analisa Tata Letak Pabrik Untuk Meminimalisasi Material Handling Pada Pabrik Sheet Metal Dengan Software Promodel. Jurnal Teknik, 3(1).

[6] Jaelani, E. 2015. Optimalisasi Sistem Pelayanan Untuk Mengurangi Antrian Dengan Pendekatan Simulasi Menggunakan Software Pro Model (Studi Kasus Pada SPBU Kadipaten, Majalengka). Jurnal Sains Manajemen \& Akuntansi. 4(1).

[7] Santoso, C. H., Tannady, H., \& Caesaron, D. 2015. Analisis Kemacetan di Jalan Lingkar Dalam Kota Jakarta (Gerbang Tol Cililitan). Teknik dan Ilmu Komputer, 4(14).

[8] Trenggonowati, D. L. 2016. Simulasi Sistem Proses Produksi di PT Jakarta Cakra Tunggal Steel Mills. Jurnal Ilmiah Teknik Industri, 4(1), 36 - 46.

[9] Ekoanindiyo, F. A. 2011. Pemodelan Sistem Antrian Dengan Menggunakan Simulasi. Jurnal Dinamika Teknik. 5(1), 72-85.

[10] Tannady, H., \& Adianto, E. 2014. Analisis Studi Gerakan Dan Simulasi Antrian Untuk Peningkatan Produktivitas Pada Pelayanan Servis Motor. Jurnal Ilmiah Teknik Industri, 2(2), 109-114.

[11] Heizer, J., \& Render, B. 2006. Operations Management. Pearson.

[12] Tannady, H., Riyan, \& Eka, W. 2014. Modifikasi Waktu Standar Pelayanan Untuk Meminimumkan Jumlah Antrian (Studi Kasus: Gerbang Tol Ancol Barat). Teknik dan Ilmu Komputer, 3(9).

[13] Rachman, T. 2016. Simulasi Model Antrian Optimal Loket Pembayaran Parkir. Jurnal Inovisi, 12(2).

[14] Khotimah, K. B. 2015. Teori Simulasi dan Permodelan: Konsep, Aplikasi dan Terapan. Wade Group.

[15] Pekarcikova, M., Trebuna, P., \& Markovic, J. 2015. Simulation as Part of Industrial Practice. International Scientific Journal about Logistics, 2(2), 5-8. 